\title{
Article
}

\section{Modularly Assembled Magnetite Nanoparticles Enhance in Vivo Targeting for Magnetic Resonance Cancer Imaging}

Ping-Ching Wu, Chia-Hao Su, Fong-Yu Cheng, Jun-Cheng Weng, Jyh-Horng Chen, Tsung-Lin

Tsai, Chen-Sheng Yeh, Wu-Chou Su, Jih Ru Hwu, Yonhua Tzeng, and Dar-Bin Shieh

Bioconjugate Chem., 2008, 19 (10), 1972-1979• DOI: 10.1021/bc800092w • Publication Date (Web): 23 September 2008

Downloaded from http://pubs.acs.org on March 4, 2009

\section{More About This Article}

Additional resources and features associated with this article are available within the HTML version:

- $\quad$ Supporting Information

- Access to high resolution figures

- $\quad$ Links to articles and content related to this article

- Copyright permission to reproduce figures and/or text from this article

\section{View the Full Text HTML}




\title{
ARTICLES
}

\section{Modularly Assembled Magnetite Nanoparticles Enhance in Vivo Targeting for Magnetic Resonance Cancer Imaging}

\author{
Ping-Ching Wu, Chia-Hao Su, Fong-Yu Cheng, Jun-Cheng Weng, Jyh-Horng Chen, Tsung-Lin Tsai, \\ Chen-Sheng Yeh, Wu-Chou Su, Jih Ru Hwu, Yonhua Tzeng, and Dar-Bin Shieh*
}

\begin{abstract}
Institute of Basic Medical Sciences and Department of Chemistry, National Cheng Kung University, Tainan 701, Interdisciplinary MRI/MRS Laboratory, Department of Electrical Engineering, National Taiwan University, Taipei 112 , Department of Internal Medicine, National Cheng Kung University Hospital, Tainan 704, Department of Chemistry, National Tsing Hua University, Hsinchu 30013, Department of Electrical Engineering and Institute of Innovation and Advanced Studies, National Cheng Kung University College of Electrical Engineering and Computer Science, Tainan 701, and Institute of Oral Medicine and Department of Stomatology and Institute of Innovation and Advanced Studies, National Cheng Kung University, Tainan 701, Taiwan. Received March 7, 2008; Revised Manuscript Received August 13, 2008
\end{abstract}

\begin{abstract}
Modularly assembled targeting nanoparticles were synthesized through self-assembly of targeting moieties on surfaces of functional nanoparticles. Specific molecular recognition of nickel nitrilotriacetate on $\mathrm{Fe}_{3} \mathrm{O}_{4}$ nanoparticles with hexahistidine tag on RGD4C peptides results in precisely controlled orientation of the targeting peptides. Better selectivity of the self-assembled RGD4C-Fe $\mathrm{O}_{4}$ nanoparticles targeting oral cancer cells than that achievable through a conventional chemical cross-link strategy was demonstrated by means of atomic absorption spectrometry (AAS). An oral cancer hamster model was applied to reveal specific in vivo targeting and MR molecular imaging contrast in cancer lesions expressing $\alpha \mathrm{v} \beta 3$ integrin. Both AAS and MRI revealed that the self-assembled nanoparticles improved the targeting efficiency and reduced the hepatic uptake as compared with the conventional chemical cross-link particles. We investigated the biosafety, biodistribution, and kinetics of the nanoparticles and found that the nanoparticles were significantly cleared from the liver and kidneys after one week. By recombining the desired targeting moiety and various functional nanoparticles through self-assembly, this new modularly designed platform has the capability of enhancing the efficiency of targeted diagnosis and therapies for a wide spectrum of biomedical applications.
\end{abstract}

\section{INTRODUCTION}

Molecular imaging of cancers provides valuable information regarding the clinical behavior of a disease and treatment response to certain therapeutic modalities. Among various molecular imaging modalities under development, magnetic resonance imaging (MRI) provides high spatial resolution, excellent perception with tomographic capabilities, outstanding soft-tissue contrast, and good anatomical detail and orientation. Conventional MRI, however, has relatively low signal contrast because of partial volume dilution effects (1). Different image contrast agents have been developed for MRI by modulating proton-T1 or -T2 relaxations using contrast agents such as manganese $\left(\mathrm{Mn}^{2+}\right)(2)$, gadolinium ethoxybenzyl diethylenetriamine pentaacetic acid (Gd-EOB-DTPA) (3), and iron oxide nanoparticles (4). These contrast agents have been developed and evaluated in the past decades for their MRI applications in the laboratory and clinical use (5-8). However, in vivo molecular targeting imaging is still in the proof-of-concept stage (9). The major challenges for targeted MRI include effective bioconjugation and the in vivo dynamics and sensitivity of the detection. This is due to the limitations of functional groups on a given targeting antibody or peptide, which can be selected for bioconjugation without compromising binding affinity.

* E-mail: dshieh@mail.ncku.edu.tw. Tel: 886-6-235-3535ext. 5377. Fax: 886-6-276-6626.
Traditional direct chemical labeling has failed to provide homogeneous functional nanoparticles with sufficient affinity to generate high MR contrast (10). Recently, a study demonstrating a comprehensive artificial synthetic approach reported an optimal size $(12 \mathrm{~nm})$ and composition of magnetic nanoparticles $\left(\mathrm{MnFe}_{2} \mathrm{O}_{4}\right)$ for in vivo targeting imaging of small tumors using trastuzumab (Herceptin) conjugation (11). However, all these efforts used to direct chemical conjugation require optimization based on each different targeting contrast agent synthesis and on the complicated combination of different targeting peptides, antibodies, and various types of functional nanoparticles, all with different surface chemistry.

Nitrilotriacetic acid (NTA) forms a stable complex with transitional metal ions such as $\mathrm{Ni}^{2+}, \mathrm{Zn}^{2+}$, and $\mathrm{Co}^{2+}$ (12). The $3 \mathrm{D}$ conformation of NTA enables stable and strong binding with polyhistidine sequences (13). Recently, NTA-modified magnetic nanoparticles attached to nickel ion $\left(\mathrm{Ni}^{2+}\right)$ can act as a general agent to separate, transport, and anchor a protein with an engineered arrangement of six consecutive histidine residues (14). This platform was capable of efficient purification of His 6-His tagged proteins that are expressed at low levels in mammalian cells (15). These studies revealed that Ni-NTA and 6-His have strong specific affinity to each other and potential application for self-assembling design.

Specific integrins, such as $\alpha v \beta 3$, have been highly expressed on the neoangiogenic endothelial cells of cancer lesions, for 
example, glioblastoma, melanoma, breast, ovarian, and prostate tumors. Some of these cancers cells overexpress the specific integrins, while their healthy counterparts do not $(16-19)$. Cyclic RGD4C (CDCRGDCFC) peptide is a potent but highly selective binder of $\alpha \mathrm{v} \beta 3$ integrins and target tumors $(20,21)$. These peptides have been successfully used for tumor imaging, cancer gene therapy, and chemotherapy (22-27).

In this article, we report the concept of modularly designed nanoparticles that separate the functional part of the nanoparticle from the targeting biomolecules. Their self-assembly through molecular recognition between the Ni-NTA molecule and the 6-histidine peptide structure enabled improved in vivo targeting imaging, effective clearance from liver and kidney, and a versatible recombination of different functional nanoparticles and different targeting biomolecules in future development.

\section{EXPERIMENTAL PROCEDURES}

Preparation of Dispersed, Water-Soluble $\mathrm{Fe}_{3} \mathrm{O}_{4}$ Nanoparticles. For preparing water-soluble and dispersed $\mathrm{Fe}_{3} \mathrm{O}_{4}$ nanoparticles, two-stage additions of protective agent and chemical coprecipitation were employed in the process $(28,29)$. Briefly, $2 \mathrm{M} \mathrm{Fe}(\mathrm{II})$ and $1 \mathrm{M} \mathrm{Fe}(\mathrm{III})$ aqueous solutions were prepared by dissolving $\mathrm{FeCl}_{2}$ and $\mathrm{FeCl}_{3}$, respectively. To produce $\mathrm{Fe}_{3} \mathrm{O}_{4}$ nanoparticles, $1 \mathrm{~mL}$ of $\mathrm{Fe}(\mathrm{II})$ and $4 \mathrm{~mL}$ of $\mathrm{Fe}(\mathrm{III})$ aqueous solutions were mixed at room temperature, followed by the addition of $0.5 \mathrm{~g}$ organic acid as adherent. Subsequently, $0.5 \mathrm{M} \mathrm{NaOH}$ was dropwise added into the mixed solution to adjust the $\mathrm{pH}$. The reaction was finished when the $\mathrm{pH}$ of the solution reached 11 . The precipitates were collected by a magnet and washed with $50 \mathrm{~mL}$ of deionized water three times, followed by addition of another $3 \mathrm{~g}$ of organic acid to achieve complete coating of the particle surface that is required for their dispersion and surface functionalization with the $-\mathrm{NH}_{3}{ }^{+}$group. The excess adherents were removed by centrifugation, and the precipitates were redispersed in deionized water. The amine functional group was a portion of the adherent used to coat the surface of the nanoparticles. The adherents are organic acids that have amine groups at the same time. The nanoparticle size was determined to be about $6.2 \pm 2.1 \mathrm{~nm}$ by TEM.

$\mathrm{Fe}_{3} \mathrm{O}_{4}$ Nanoparticle Modification, Peptide Synthesis, and Conjugation to Nanoparticles. $\mathrm{Fe}_{3} \mathrm{O}_{4}-\mathrm{NH}_{3}{ }^{+}$nanoparticles and NTA were conjugated as previously described (30). Briefly, $100 \mu \mathrm{L}$ of $0.2 \mathrm{M} \mathrm{Fe}_{3} \mathrm{O}_{4}$ nanoparticles were added to $46 \mu \mathrm{L}$ of $0.22 \mathrm{M} N^{\alpha}, N^{\alpha}$-Bis(carboxymethyl)-L-lysine, $20 \mu \mathrm{L}$ of $55 \%(w /$ w) glutaraldehyde, and $334 \mu \mathrm{L}$ of $\mathrm{H}_{2} \mathrm{O}$; the mixture was then stirred at room temperature (approximately $25^{\circ} \mathrm{C}$ ) for $4 \mathrm{~h}$. The $\mathrm{Fe}_{3} \mathrm{O}_{4}$ nanoparticle can conjugate with NTA when glutaraldehyde and $\mathrm{NaBH}_{3} \mathrm{CN}$ were added. The amine group can conjugate with the aldehyde group of glutaraldehyde to form the $\mathrm{C}=\mathrm{N}$ form; then, the $\mathrm{C}=\mathrm{N}$ form was reduced to the $\mathrm{C}-\mathrm{N}$ form with $\mathrm{NaBH}_{3} \mathrm{CN}$. Therefore, glutaraldehyde was a linker between the nanoparticle and NTA. The resulting precipitate $\left(\mathrm{Fe}_{3} \mathrm{O}_{4}\right.$-NTA) was resuspended in $1 \mathrm{~mL}$ of $\mathrm{H}_{2} \mathrm{O}$ and then centrifuged at $13000 \mathrm{rpm}$ for $20 \mathrm{~min}$ to remove the excess NTA. After the precipitate had been washed three times with milliQ water, resuspended in $1 \mathrm{~mL}$ of $1.0 \mathrm{M} \mathrm{NiSO}_{4}$, stirred at room temperature for $8 \mathrm{~h}$, and then centrifuged again to obtain the $\mathrm{Fe}_{3} \mathrm{O}_{4}-\mathrm{NTA}^{-\mathrm{Ni}^{2+}}$ complex, cyclic RGD4C with a 6-histidine peptide residue on the C-terminal (CDCRGDCFCGGGGGGHHHHHH) was synthesized (Genesis Biotech Inc., Taipei, Taiwan) and evaluated for self-assembly on the nanoparticle surfaces. Twenty-three microliters of $8.9 \mathrm{mM}$ RGD4C-6histidine peptide was added to $1 \mathrm{~mL}$ of $20 \mu \mathrm{M}$ aqueous $\mathrm{Ni}$ NTA-modified $\mathrm{Fe}_{3} \mathrm{O}_{4}$ to obtain self-assembled $\mathrm{Fe}_{3} \mathrm{O}_{4}-\mathrm{NTA}$ $\mathrm{Ni}-\mathrm{RGD} 4 \mathrm{C}$ nanoparticles. As a control, the original $\mathrm{Fe}_{3} \mathrm{O}_{4}$ nanoparticles, with an amine functional group on the surface, were conjugated with the same concentration of RGD4C peptide through a conventional chemical cross-linking strategy using glutaraldehyde (nanoparticles/peptides $=1: 10$ ). After the samples had been incubated at $4{ }^{\circ} \mathrm{C}$ overnight, they were centrifuged at $13000 \mathrm{rpm}$ for $10 \mathrm{~min}$, and the supernatant discarded to obtain the targeting nanoparticles.

Cell Culture and Maintenance. The HCDB-1 is a hamster oral squamous cell carcinoma cell line previously isolated and characterized by Professor Lin of National Yang-Ming University, Taiwan (31). The NIH3T3 mouse fibroblast cell line and human oral squamous cell carcinoma line (SCC15) were purchased from the American type Culture Collection (ATCC). OEC-M1 was established by Dr. CL Meng from a Taiwanese male oral cancer patient with areca quid chewing history. HCDB-1 and OEC-M1 were maintained in RPMI 1640 medium (Invitrogen Corp., Carlsbad, CA). SCC15 cells were maintained in Dulbecco's Modified Eagle's medium (Invitrogen Corp., Carlsbad, CA). NIH3T3 cells were maintained in Dulbecco's Modified Eagle's medium (Invitrogen Corp., Carlsbad, CA). These media were supplemented with $10 \%$ fetal bovine serum (FBS; Invitrogen Corp., Carlsbad, CA) and 1\% penicillin-streptomycin (Invitrogen Corp., Carlsbad, CA). Healthy oral mucosal epithelial cells were derived from excessive retromolar gingival tissue of healthy donors with consent during surgical extraction of the third molar teeth. The oral keratinocytes were purified using a previously described method (32). The culture was maintained in serum-free keratinocyte growth medium (Cascade Biologics, Inc., Portland, OR) with keratinocyte growth supplement. Passage-4 cultures were used in the analysis for all studies. All cell lines were incubated at $37{ }^{\circ} \mathrm{C}$ in an atmosphere with $5 \% \mathrm{CO}_{2}$.

Ligand Competition Assay. We did a ligand competition assay using free cyclic RGD4C peptide (Genesis Biotech Inc., Taipei, Taiwan) as a competitor for the RGD-4 conjugated magnetite particles. The free RGD4C (CDCRGDCFCGGGGGG) was added to the medium to a final concentration of $3 \mu \mathrm{M}$ for $1 \mathrm{~h}$ to saturate the receptor molecules on the cell surface. After they had been washed with PBS, the cells were added to a different concentration of $\mathrm{Fe}_{3} \mathrm{O}_{4}$-NTA-Ni-RGD4C and analyzed using AAS.

Biocompatibility Assay for the $\mathrm{Fe}_{3} \mathrm{O}_{4}$-NTA-Ni-RGD4C. NIH3T3 and HCDB-1 cells were cultured in 96-well culture plates at a density of $5 \times 10^{3}$ cells/well. $\mathrm{Fe}_{3} \mathrm{O}_{4}$-NTA-Ni-RGD4C nanoparticles of different concentrations $(0.003-9.4 \mathrm{mg} / \mathrm{mL})$ were added to each culture well and incubated for $24 \mathrm{~h}$. Cell viability was determined using a 5-dimethylthiazol-2-yl-2,5diphenyl tetrazolium bromide (MTT) assay (33). The systemic toxicity of the $\mathrm{Fe}_{3} \mathrm{O}_{4}$-NTA-Ni-RGD4C nanoparticles were determined in vivo using 6 -week-old BALB/c mice $(n=36)$ randomly assigned to three experimental groups with different dosages of nanoparticles $(1,2.5$, and $5 \mathrm{mg} / \mathrm{kg}$ groups) and one PBS control group ( $n=9$ mice/group). The nanoparticles were injected into the tail vein of each mouse. The survival and pathological symptoms and signs of each mouse were monitored for a period of one month.

Animals and Tumor Model. The male Syrian gold hamsters were purchased from the National Laboratory Animal Center (Taipei, Taiwan) and BALB/c mice from the National Cheng Kung University Laboratory Animal Center (Tainan, Taiwan). All animals were given humane care in compliance with the institution's guidelines for maintenance and use of laboratory animals in research. All experimental protocols involving live animals were reviewed and approved by the Animal Experimentation Committee of Nation Cheng Kung University. HCDB1 tumor xenografts were established by injecting $10^{7}$ tumor cells in $100 \mu \mathrm{L}$ of normal saline into the right buccal pouch using a 27 -gauge needle. Tumors were normally visible one week after the injection. For MRI experiments, the hamsters 
were anesthetized with $2 \%$ isoflurane (Abbott Laboratories, Abbott Park, IL) mixed with $100 \% \quad \mathrm{O}_{2}$ delivered using a veterinary anesthesia delivery system (ADS 1000; Engler Engineering Corp., Hialeah, FL). The animals were given an overdose of $2.5 \%$ pentothal (Abbott Laboratories, Abbott Park, IL). Their tumor and organ tissues were harvested in the following experiments.

Atomic Absorption Spectrometry Analysis. Cells $\left(5 \times 10^{6}\right.$ cells) in a $10 \mathrm{~cm}^{2}$ culture dish were incubated with different concentrations of nanoparticles or PBS at $4{ }^{\circ} \mathrm{C}$ for $1 \mathrm{~h}$. After the cells had been washed three times with cold PBS, $5 \mathrm{~mL}$ of nitric acid was added to dissolve the cells. The total lysate was subjected to atomic absorption spectroscopy (AAS) (Unicam Solaar M6 series) analysis. The tumor and organ tissues were surgically harvested from the hamsters, and then $1 \mathrm{~g}$ of the tumor and organ tissues were isolated from the harvested tissue. After they had been homogenized, they were placed into a centrifuge tube containing $30 \mathrm{~mL}$ of nitric acid $(12 \mathrm{M})$, and incubated for 3 days to permit complete dissolution of the tissues. The obtained liquid was analyzed using AAS.

Magnetic Resonance Imaging. Sequential MRI acquisition was done in a 3T MR imager (Biospec System; Bruker BioSpin MRI GmbH, Ettlingen, Switzerland) equipped with a highperformance gradient coil (inner diameter $=12 \mathrm{~cm}$; maximal gradient strength $=200 \mathrm{mT} \mathrm{m}^{-1}$ ) and a quadrature coil (inner diameter $=10 \mathrm{~cm}$ ) for $\mathrm{RF}$ transmission and reception. The hamsters were anesthetized using 2\% isoflurane (Abbott Laboratories, Abbott Park, IL) mixed with $100 \% \mathrm{O}_{2}$ delivered using a veterinary anesthesia delivery system (ADS 1000; Engler). $\mathrm{Fe}_{3} \mathrm{O}_{4}$-NTA-Ni-RGD4C yielded signal contrast using a T2* pulse sequence $(\mathrm{TR} / \mathrm{TE}, 743 / 5 \mathrm{~ms}$; MTX, $256 \times 256 \times 25)$.

Measurements MR Image of $\mathrm{Fe}_{3} \mathrm{O}_{4}$ in Tumor Site with Matlab Workstation. Three sequential axial images $(1.5 \mathrm{~mm}$ thickness, original magnification $\times 1.5)$ of each of the 75 potential implant sites were selected $(N=225)$ using Matlab software to analysis. The operator determined the red circle of the ROI in all sites. The spatial coordinate tool $(x, y)$ was manually set to define a circular or oval ROI at the same anatomic location on each of the 3 axial images. The average signal intensity of each ROI relative to that of the control (fish oil capsule indicator) was calculated. The alterations in the MR signal of the tumor site in a time series $(0,24$, and $48 \mathrm{~h})$ were compared to that before injection. The same method was applied for the calculation of MR signal alterations in the liver.

Histological Examination. For Prussian blue, hematoxylin, and eosin staining (H\&E), the tumor tissue was fixed with $4 \%$ paraformaldehyde and paraffin-sectioned. Tissue samples were sliced into $5-\mu \mathrm{m}$-thick sections and then incubated with $2 \%$ potassium ferrocyanide in $6 \%$ hydrochloric acid for $30 \mathrm{~min}$. After they had been washed, they were counterstained with Giemsa solution. The specimens were then mounted and examined under a light microscope (BH-2; Olympus, Tokyo, Japan).

Statistical Analysis. All experiments were repeated at least three times and the values are means \pm standard deviation. Statistical analyses were done using Student's $t$-test. Statistical significance was set at $p<0.05$.

\section{RESULT AND DISCUSSION}

We previously demonstrated that self-assembly of 6-His tagged RGD4C peptide to nanoparticle surface improved molecular orientation control and cancer cell targeting in vitro (30). In this article, the strategy was evaluated for in vivo cancer imaging. The superparamagnetic $\mathrm{Fe}_{3} \mathrm{O}_{4}$ nanoparticles $(6.2 \pm 2.1$ $\mathrm{nm}$ ) in aqueous solution were conjugated with RGD4C peptide through traditional chemical conjugation $\left(\mathrm{Fe}_{3} \mathrm{O}_{4}-\mathrm{RGD} 4 \mathrm{C}\right)$ or the
Scheme 1. Schematic Diagram Illustrating Two Different Bioconjugation Methods ${ }^{a}$

A.
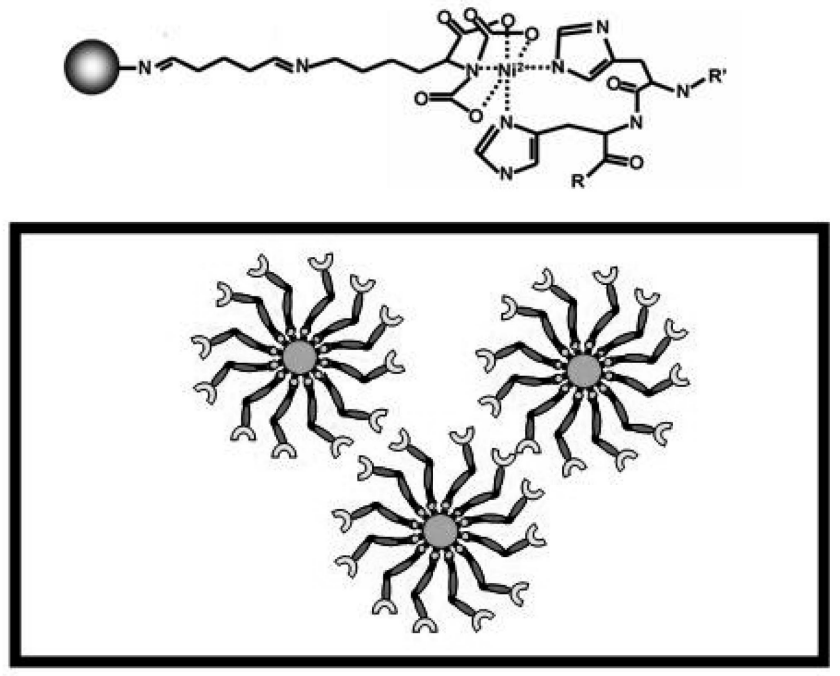

B.
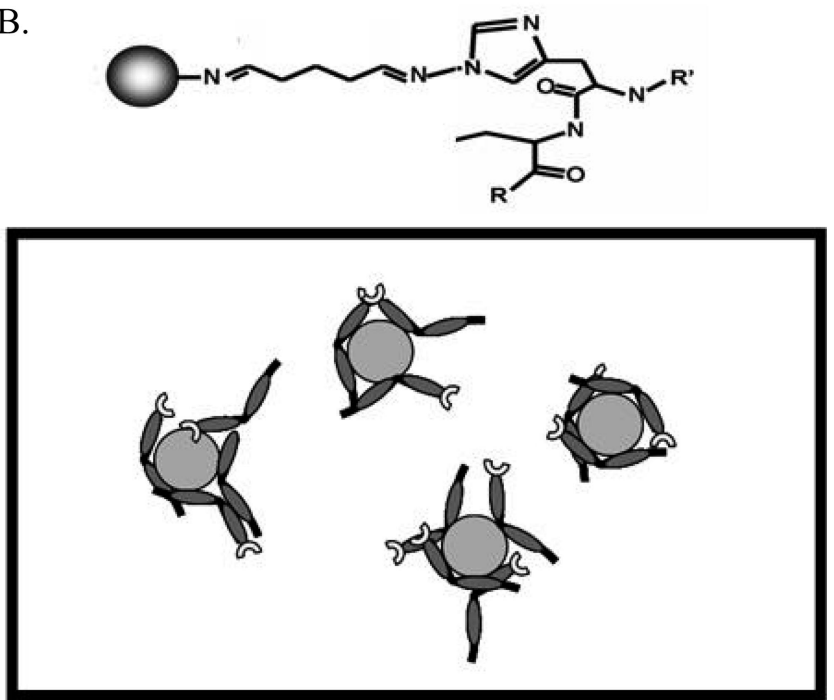

${ }^{a}$ (A) The modular-targeting nanoparticles with orientation control made through self-assembly of the molecular key $\left(\mathrm{Ni}^{2+}\right.$-NTA) on the particle and the molecular lock (6-His tag) on the peptide. (B) The traditional chemical cross-linking using glutaraldehyde usually derived a peptide-nanoparticle complex with random molecular orientation because multiple sites on the peptide are available for conjugation.

self-assembly on the particle surface method $\left(\mathrm{Fe}_{3} \mathrm{O}_{4}-\mathrm{NTA}-\mathrm{Ni}\right.$ RGD4C) (Scheme 1).

Cytotoxicity of $\mathrm{Fe}_{3} \mathrm{O}_{4}$-NTA-Ni-RGD4C Nanoparticles. The cytotoxicity of the nanoparticles was evaluated using both HCDB1 (Figure 1A) and NIH3T3 cells (seeSupporting Information S1) using MTT assay. The results showed satisfactory $(>80 \%$ ) biocompatibility at a particle concentration below 0.376 $\mathrm{mg} / \mathrm{mL}$ (Figure 1A) in both cell lines. This particle concentration was sufficient to produce a significant MR contrast effect in vivo (28). The inhibition in cell growth at high dosages (1.88 and $9.4 \mathrm{mg} / \mathrm{mL}$ ) may attribute to the interaction of the targeting peptide with the integrin signaling pathway. The nanoparticle concentrations were referenced to iron concentration determined from AA (atomic absorption) spectrometry. Selective binding of RGD-4C peptide to $\alpha v \beta 3$ and $\alpha v \beta 5$ integrins in human 
A.

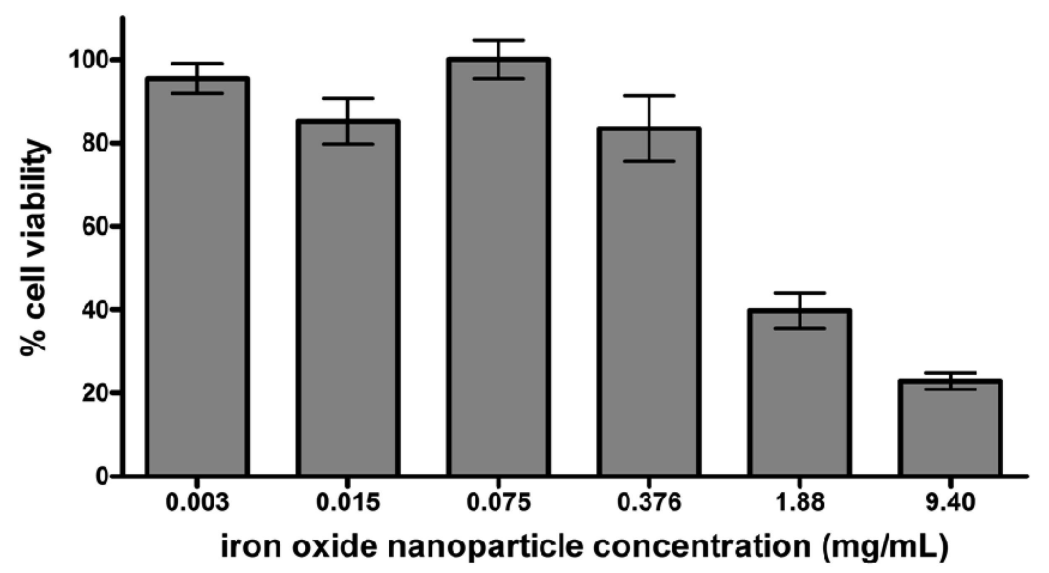

B.

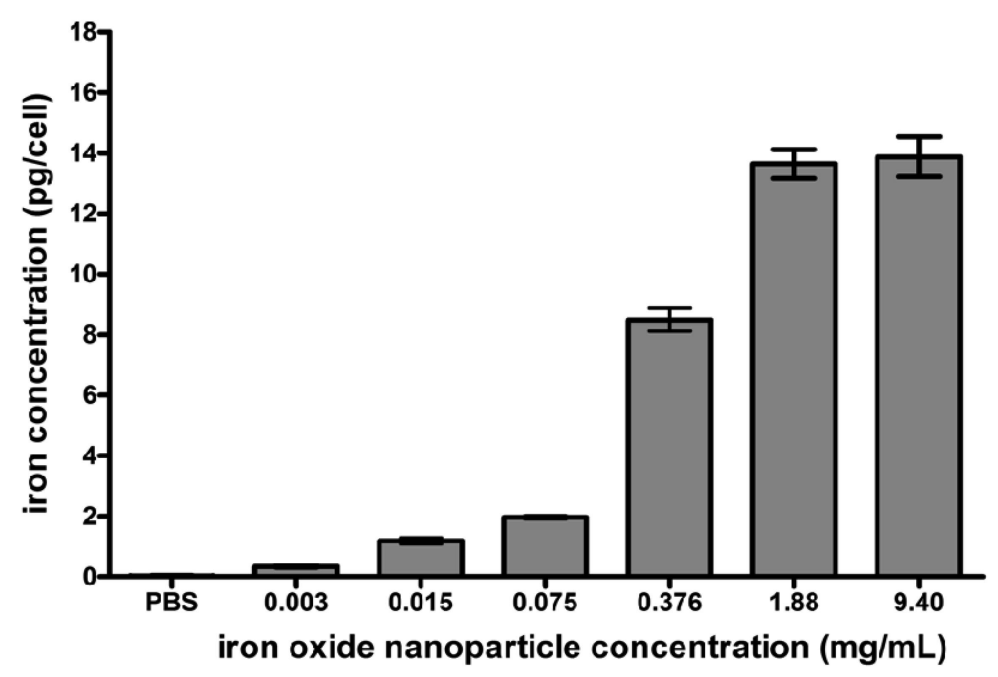

Figure 1. The biocompatibility of the nanoparticles was evaluated using MTT assay. (A) The cell viability of HCDB1 with different nanoparticle concentrations was analyzed. Biocompatibility was satisfactory at doses lower than $1.25 \mu \mathrm{M}$. Targeting of the self-assembled Fe $\mathrm{O}_{4}$-NTA-NiRGD4C nanoparticles to HCDB1 cells as a function of the nanoparticle concentration was evaluated. (B) $\mathrm{HCDB} 1 \mathrm{cells}\left(5 \times 10^{6} \mathrm{cells} / \mathrm{dish}\right)$ were cultured in $10 \mathrm{~cm}^{2}$ culture dishes and exposed to nanoparticles of different concentrations for $1 \mathrm{~h}$ before a quantitative atomic absorption spectroscopy analysis of the iron in the cells.

umbilical endothelial cells (HUVECs) have been reported to induce cellular detachment, caspase-8 activation, and apoptosis (34).

Dose-Dependent Affinity Targeting of $\mathrm{Fe}_{3} \mathrm{O}_{4}$-NTA-NiRGD4C Nanoparticles. The dosage-dependent affinity targeting of $\mathrm{Fe}_{3} \mathrm{O}_{4}$-NTA-Ni-RGD4C nanoparticles to HCDB1 cells that express $\alpha v \beta 3$ was analyzed in vitro by AAS quantification of total cell lysate. A dosage-dependent affinity targeting of HCDB-1 cells by the self-assembled nanoparticles was observed (Figure 1B). The targeting reached a plateau at $1.88 \mathrm{mg} / \mathrm{mL}$ concentration, while it was about $64 \%$ of the plateau at the biocompatible concentration of $0.376 \mathrm{mg} / \mathrm{mL}$. We then evaluated the selectivity of the targeting nanoparticles toward cancerous oral epithelial cells at $0.376 \mathrm{mg} / \mathrm{mL}$ of nanoparticle concentration.

Selective Targeting of $\mathrm{Fe}_{3} \mathrm{O}_{4}$-NTA-Ni-RGD4C Nanoparticles. Three oral cancer cell lines (HCDB-1, OEC-M1, and SCC15) and one primary culture normal human oral keratinocytes (hNOK) were targeted by $0.376 \mathrm{mg} / \mathrm{mL}$ of $\mathrm{Fe}_{3} \mathrm{O}_{4}$-NTA$\mathrm{Ni}-\mathrm{RGD} 4 \mathrm{C}$ or $\mathrm{Fe}_{3} \mathrm{O}_{4}-\mathrm{RGD} 4 \mathrm{C}$ at $4{ }^{\circ} \mathrm{C}$ for $1 \mathrm{~h}$ to evaluate (1) whether $\mathrm{Fe}_{3} \mathrm{O}_{4}$-NTA-Ni-RGD4C self-assembled nanoparticles selectively bind to the selected cancer cells but not their normal counterpart healthy cells and (2) whether this modularly assembled complex exhibits at a higher targeting efficiency than that of the conventional direct chemical conjugation using the same total amount of targeting peptide for conjugation. The cells were processed for AAS analysis to calculate the total amount of the nanoparticles targeted onto the cells. The cancer cells showed a significantly $(P<0.0001)$ higher targeting efficiency than did the hNOK (range from 7.2:1 to 3.5:1). In all groups of the in vitro targeting analysis, the self-assembled $\mathrm{Fe}_{3} \mathrm{O}_{4}$-NTA$\mathrm{Ni}$ - RGD4C nanoparticles outperformed the $\mathrm{Fe}_{3} \mathrm{O}_{4}-\mathrm{RGD} 4 \mathrm{C}$ nanoparticles $(P<0.001)$ (Figure $2 \mathrm{~A})$.

To examine the specifics of the targeting, we did a ligand competition assay. The results indicated that free RGD4C peptide was highly specific and selective, as it significantly restricts the targeting efficiency in all groups with a range 23-33\% for self-assembled $\mathrm{Fe}_{3} \mathrm{O}_{4}$-NTA-Ni-RGD4C nanoparticles and $40-53 \%$ for conventional $\mathrm{Fe}_{3} \mathrm{O}_{4}$-RGD4C nanoparticles (Figure 2B). It is well-known that cyclic RGD4C peptide has a specific affinity for $\alpha v \beta 3$ integrins that are selectively expressed in some tumor cells and their neoangiogenic tissue $(20,21,35)$. An improved targeting efficiency may attribute to the increased molecular-orientation control through the on-particle self-assembly of the targeting peptide enabled by the engineered affinity peptide "lock" (6-histidine) for the Ni-NTA "key" on the nanoparticle surface (Scheme 1A). 


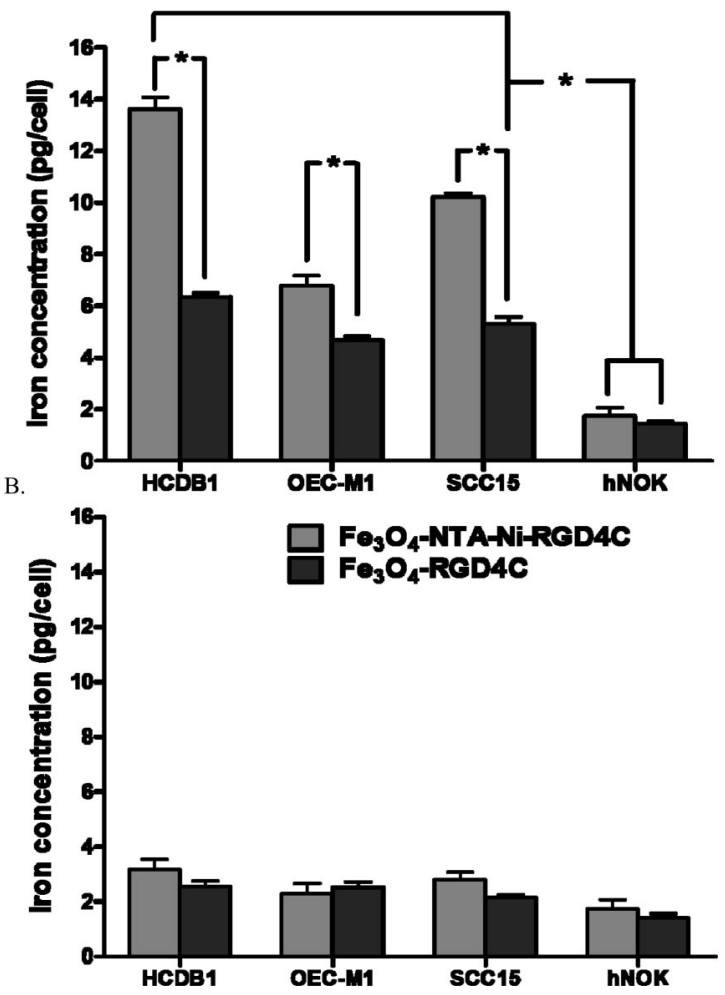

Figure 2. Atomic absorption spectroscopy analysis of the specificity and targeting efficiency for $\mathrm{Fe}_{3} \mathrm{O}_{4}$-RGD4C nanoparticles and selfassembled $\mathrm{Fe}_{3} \mathrm{O}_{4}$-NTA-Ni-RGD4C nanoparticles to oral cancer cells compared to their specificity and targeting efficiency for healthy oral keratinocytes (hNOK). (A) Both types of nanoparticles showed improved cancer cell targeting. Self-assembled targeting nanoparticles consistently outperformed the conventionally prepared nanoparticles. (B) A competition assay was done using RGD4C peptide. The affinity targeting of the nanoparticles was significantly inhibited in all groups. $*, P<0.001$. The iron concentration for the untreated cells in all groups were between 0.06 and $0.09 \mathrm{pg} / \mathrm{cell}$. The iron concentration of the nanoparticle treated cells presented in the chart has been subtracted from their baseline iron levels.

Biocompatibility of $\mathrm{Fe}_{3} \mathrm{O}_{4}$-NTA-Ni-RGD4C Nanoparticles in Vivo. To further explore in vivo use of the selfassembled $\mathrm{Fe}_{3} \mathrm{O}_{4}$-NTA-Ni-RGD4C nanoparticles, we analyzed their in vivo biocompatibility. The hemocompatibility of $\mathrm{Fe}_{3} \mathrm{O}_{4}$ NTA-Ni has been reported (30). To determine the in vivo systemic toxicity, the $\mathrm{Fe}_{3} \mathrm{O}_{4}$-NTA-Ni-RGD4C nanoparticles were injected into the tail vein of 36 6-week-old BALB/c mice with PBS as a control. We monitored the survival and pathological symptoms and signs of each mouse for one month. Only 2 mice died, 1 in the $2.5 \mathrm{mg} / \mathrm{kg}$ group on day 17 , and 1 in the $5 \mathrm{mg} / \mathrm{kg}$ group on day 10 . These results suggested that the RGD4C self-assembled $\mathrm{Fe}_{3} \mathrm{O}_{4}$ nanoparticles are safe for in vivo applications within the dosage range for effective MR contrast (Figure 3) (28).

Molecular MR Imaging of Oral Cancer Using $\mathrm{Fe}_{3} \mathrm{O}_{4}$ NTA-Ni-RGD4C Nanoparticles. We then evaluated the molecular imaging of cancer lesions for specific integrin membrane protein in orthotopic hamster buccal pouch oral cancer model. For the MRI of each tumor lesion, we injected $\mathrm{Fe}_{3} \mathrm{O}_{4}$-NTA$\mathrm{Ni}-\mathrm{RGD} 4 \mathrm{C}$ or the control $\mathrm{Fe}_{3} \mathrm{O}_{4}-\mathrm{Ni}-\mathrm{NTA}$ at a concentration of $5 \mathrm{mg} / \mathrm{kg}$ through the right jugular vein and then sequentially acquired images at $1,6,12,24$, and $48 \mathrm{~h}$ intervals in a $3 \mathrm{~T} \mathrm{MR}$ imager. $\mathrm{Fe}_{3} \mathrm{O}_{4}$-NTA-Ni-RGD4C yielded a specifically targeted negative contrast image of the oral cancer lesion within $24 \mathrm{~h}$ using a T2* pulse sequence (TR/TE, 743/5 ms; MTX, $256 \times$ $256 \times 25)($ Figure $4 \mathrm{~A})$. The signal contrast persisted for at least $48 \mathrm{~h}$ after self-assembled $\mathrm{Fe}_{3} \mathrm{O}_{4}$-NTA-Ni-RGD4C nanoparticles

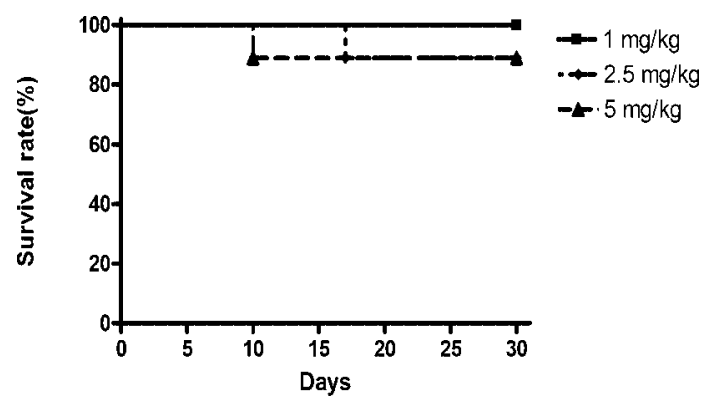

Figure 3. Survival analysis of BALB/c mice exposed to $1,2.5$, and 5 $\mathrm{mg} / \mathrm{kg}$ of the self-assembled $\mathrm{Fe}_{3} \mathrm{O}_{4}$-NTA-Ni-RGD4C targeting nanoparticles $(n=9)$. In vivo biocompatibility was satisfactory.

A.
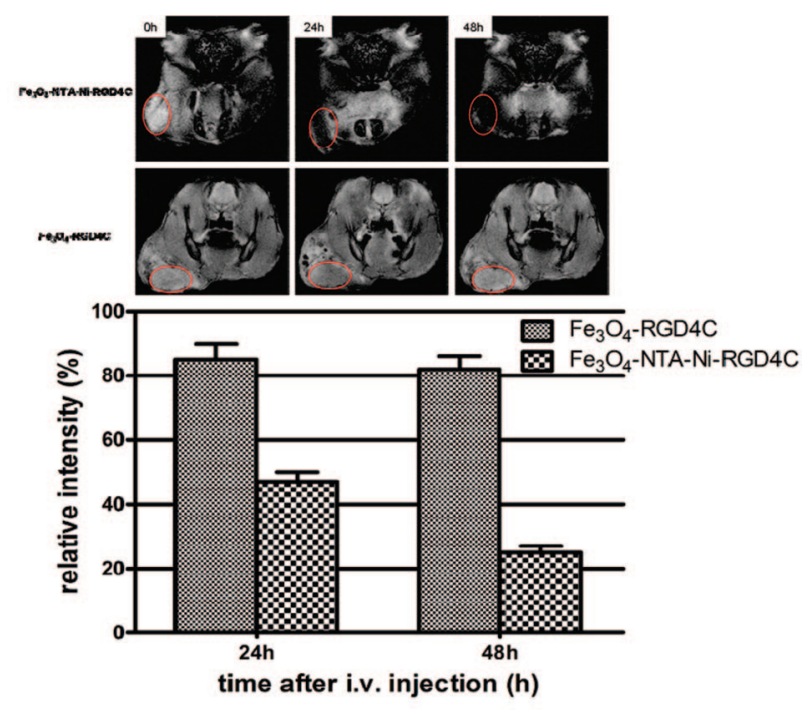

B.
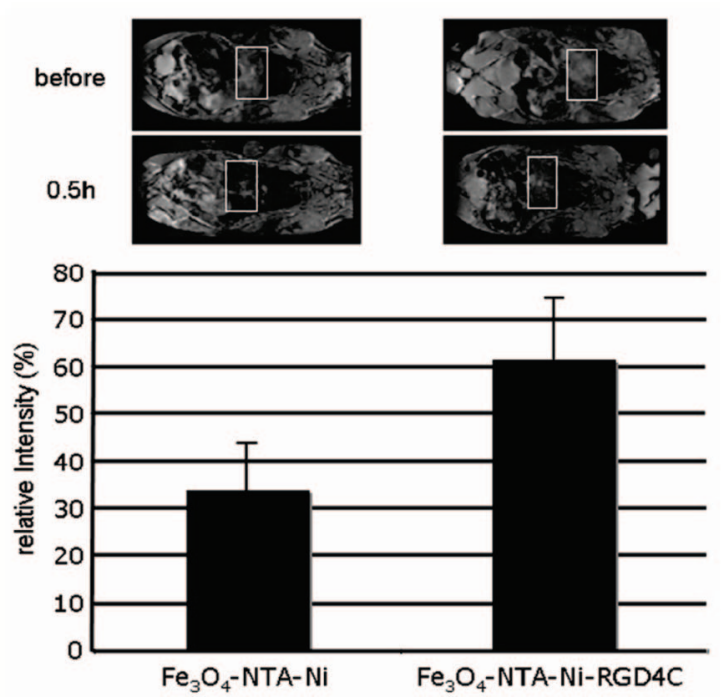

Figure 4. (A) In vivo molecular magnetic resonance imaging of oral cancer in a hamster model shows significant inverse contrast $\mathrm{T} 2 *$ images 24 and $48 \mathrm{~h}$ after i.v. injection of the $\mathrm{Fe}_{3} \mathrm{O}_{4}$-NTA-Ni-RGD4C and $\mathrm{Fe}_{3} \mathrm{O}_{4}$ - $\mathrm{RGD} 4 \mathrm{C}$ nanoparticles. (The red circled areas indicate the orthotopically induced tumor lesion). (B) Quantitative measurement (Matlab software) of tissue signal intensity showed that modifying the magnetite nanoparticles with the self-assembled targeting moiety (RGD4C) significantly decreased their absorption in the liver.

had been intravenously injected. In order to evaluate whether the conjugation of RGD4C to iron oxide nanoparticles would affect its hepatic uptake, $\mathrm{Fe}_{3} \mathrm{O}_{4}$-NTA-Ni $(5 \mathrm{mg} / \mathrm{kg}$ ) with or without self-assembly with RGD4C-6-his were injected into each hamster's jugular vein, and then a series of MRI taken. 

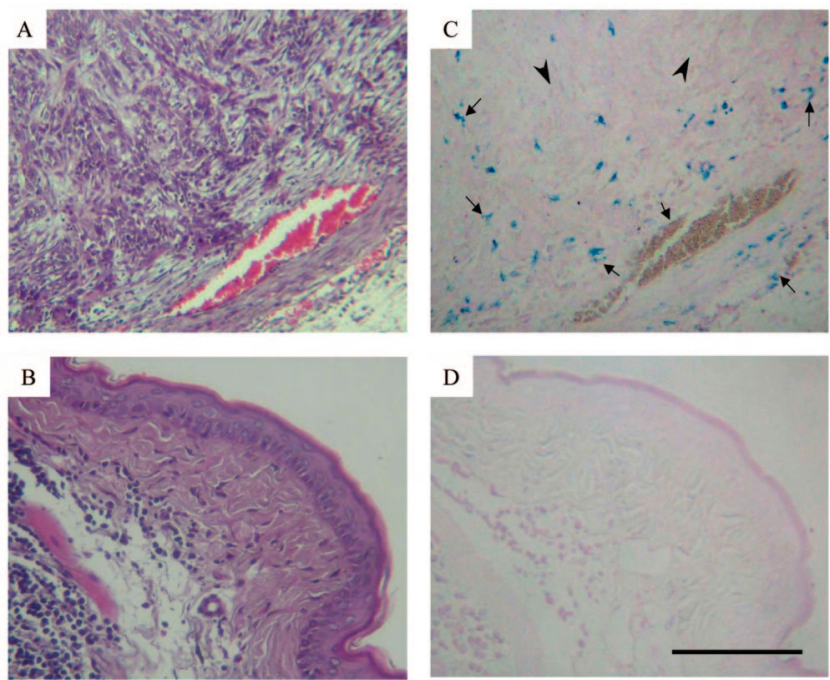

Figure 5. Oral cancer tissue and healthy oral mucosal tissue from the same hamster taken $24 \mathrm{~h}$ after i.v. injection of the $\mathrm{Fe}_{3} \mathrm{O}_{4}-\mathrm{NTA}-\mathrm{Ni}$ RGD4C nanoparticles was processed for histological and histochemical analysis. (A) Hematoxylin and eosin-stained cancer tissue showed that cancer cells had invaded through the connective tissue with numerous neoangiogenic blood vessels. (B) healthy oral mucosal tissue on the contralateral site. (C) Pearl's iron stain of the adjacent section showed a diffuse bluish-purple in the tumor tissue (arrowheads) with significant accumulation in the endothelial cells (arrows) and some macrophages. (D) Healthy oral mucosal tissue showed only pink background counterstain. (Scale bar: $100 \mu \mathrm{m}$.)

The signal intensity of the nanoparticles was quantified in 10 randomly selected areas of the liver. The self-assembled $\mathrm{Fe}_{3} \mathrm{O}_{4^{-}}$ NTA-Ni-RGD4C showed significantly lower hepatic uptake (39\% reduction of signal intensity $30 \mathrm{~min}$ after i.v. injection) than the $\mathrm{Fe}_{3} \mathrm{O}_{4}$-NTA-Ni without a targeting peptide $(66 \%)$ (Figure 4B).

Histological Analysis. To explore the distribution of $\mathrm{Fe}_{3} \mathrm{O}_{4}$ NTA-Ni-RGD4C nanoparticles in tumor and healthy oral mucosal tissue, a histological examination of formalin-fixed paraffin-embedded tumor and healthy tissue was performed on the surgically removed specimens $24 \mathrm{~h}$ after delivery of the nanoparticles. Tissue samples were analyzed for H\&E (Figure 5A,B) or Pearl's iron stain (Figure 5C,D). Tumor cells (upper left region of Figure 5A) showed light bluish-purple Pearl's iron staining (Figure 5B, arrowheads) in contrast to healthy oral mucosal tissue (Figure 5C) that showed only pinkish background staining (Figure 5D). This indicates an increased uptake of the targeting iron oxide nanoparticles by the tumor cells. Some of the capillary structure of the tumor lesion and the surrounding neoangiogenic blood vessels showed a strong bluish staining (Figure 5B, arrows) from accumulated targeting nanoparticles, which was not present in healthy oral mucosal tissue (Figure 5D).

In Vivo Targeting Efficiency in the Tumor Lesions Quantified Using AAS. The in vivo targeting efficiency in the tumor lesions was quantified using AAS at a series of time points after $\mathrm{Fe}_{3} \mathrm{O}_{4}$-RGD4C nanoparticles or self-assembled $\mathrm{Fe}_{3} \mathrm{O}_{4}$ NTA-Ni-RGD4C nanoparticles had been intravenously injected. The $\mathrm{Fe}^{2+}$ concentration peaked $24 \mathrm{~h}$ after the injection for both types of nanoparticles and then decreased to the original background level after $72 \mathrm{~h}$ (Figure 6A). At all observation points, significantly higher $\mathrm{Fe}^{2+}$ concentration was detected in tumor tissue targeted by $\mathrm{Fe}_{3} \mathrm{O}_{4}-\mathrm{NTA}-\mathrm{Ni}-\mathrm{RGD} 4 \mathrm{C}$ nanoparticles than in tumor tissue targeted by $\mathrm{Fe}_{3} \mathrm{O}_{4}$ - $\mathrm{RGD} 4 \mathrm{C}$ nanoparticles. The MR image analysis show significant decrease in the tumor signal intensity (47\%) from 0 to $24 \mathrm{~h}$ (Figure 4A) followed by a decrease from 24 to $48 \mathrm{~h}(25 \%)$. Quantitative analysis of AA
A.
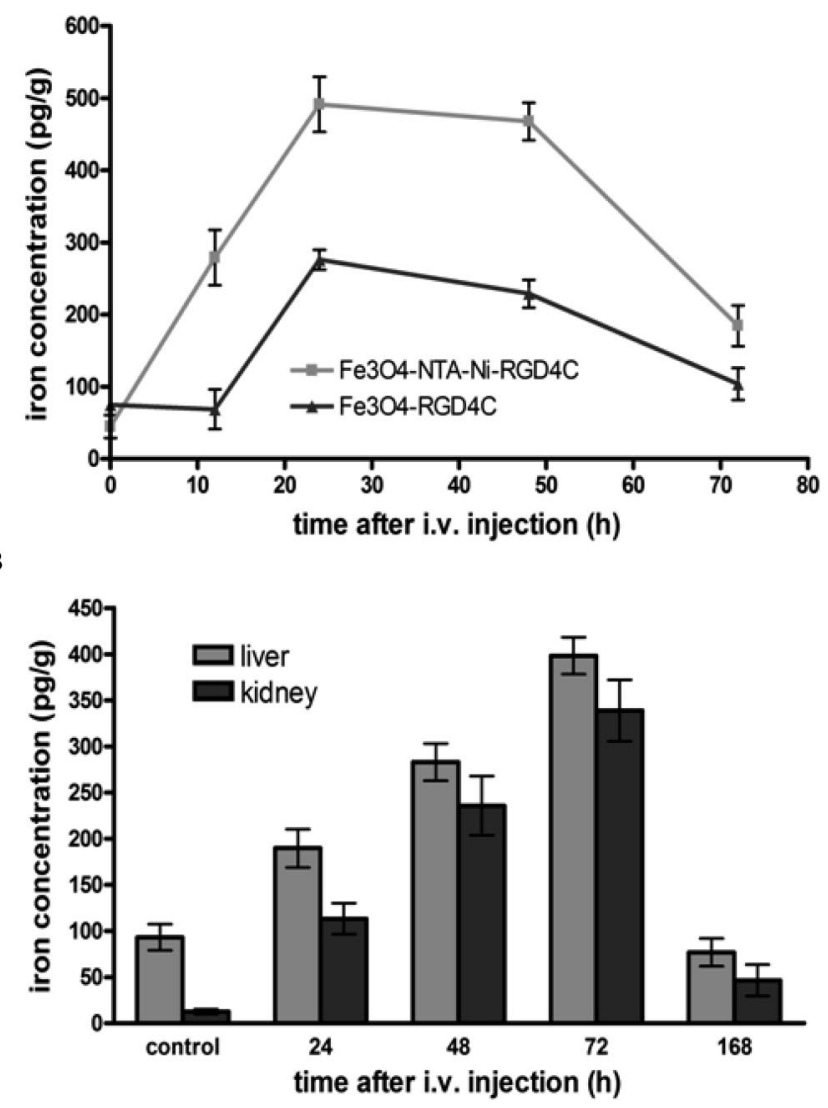

Figure 6. Hamster oral cancer lesions were surgically removed at each time point indicated and then evaluated, using atomic absorption spectroscopic quantitative analysis, for nanoparticle accumulation. (A) The accumulation of $\mathrm{Fe}_{3} \mathrm{O}_{4}$-NTA-Ni-RGD4C and $\mathrm{Fe}_{3} \mathrm{O}_{4}$-RGD4C nanoparticles (iron concentration). (B) The accumulation of $\mathrm{Fe}_{3} \mathrm{O}_{4}$-NTA$\mathrm{Ni}-\mathrm{RGD} 4 \mathrm{C}$ in the liver and the kidneys was analyzed after i.v. injection of the nanoparticles.

revealed no statistical difference between iron oxide concentrations at 24 and $48 \mathrm{~h}(p=0.11)$. The decrease in the MRI signal intensity at $48 \mathrm{~h}$, while slightly decreasing the tissue iron concentration, could be explained by the aggregation of iron oxide nanoparticles in tissue or cells. A previous report demonstrated that the aggregation of magnetic particles can enhance the $\mathrm{T} 2$ or $\mathrm{T} 2 *$ volume in the magnetic field $(36,37)$. Nevertheless, all these data indicate that the self-assembled targeting iron oxide nanoparticles in the current report could be retained in the tumor site for at least $48 \mathrm{~h}$ for prolonged observation.

Biodistribution and Excretion of Iron Oxide Nanoparticles. The in vivo biodistribution of the $\mathrm{Fe}_{3} \mathrm{O}_{4}-\mathrm{NTA}-\mathrm{Ni}$ RGD4C nanoparticles in the liver and kidneys over time was evaluated using AAS analysis. The organs were processed for AAS analysis as described in the Experimental Procedures. The liver and kidneys were surgically removed from the hamsters at 24, 48, 72, and $168 \mathrm{~h}$ after injection with $\mathrm{Fe}_{3} \mathrm{O}_{4}$-NTA-NiRGD4C or PBS. Nanoparticles gradually accumulated in the liver and kidneys and peaked $72 \mathrm{~h}$ after injection (Figure 6B). The iron signal in the liver tissue returned to the normal level $168 \mathrm{~h}$ after i.v. injection, while decreasing to $8 \%$ of the peak level in kidney tissue at the same time point.

Using MRI to retrieve the information of molecular imaging and to track the progression of a certain disease targeting is highly valuable for disease management. A wide range of MR molecular imaging approaches for cancers have been extensively investigated $(38,39)$. However, the key has been the design of imaging probes that can sensitively relay 
specific molecular recognition of certain components or pathways in cancer cells with high sensitivity. This allows for signal acquisition and image reconstruction. In vivo iron oxide-based molecular imaging modalities have also been recently reported $(40,41)$. To the best of our knowledge, our findings here are the first to illustrate the concept of functional nanoparticles that are modularly assembled for in vivo targeted molecular imaging.

As stated above, integrin $\alpha v \beta 3$ is selectively overexpressed in the cancer and neoangiogenic blood vessels, but at a much lower level in mature quiescent cells (42). As a result of such expression specificity, it was chosen as the target for molecular imaging in the current study. We showed, both in vivo and in vitro, that the molecular self-assembled modular design performed better than the conventional direct chemical cross-link design in affinity targeting of cancer cells. MRI, using selfassembled nanoparticles, clearly demonstrated a cancerspecific image contrast and a relatively normal image contrast of liver tissue, superior to MRI using non-self-assembled nanoparticles. Nanoparticles are known to be easily trapped and absorbed by the RES system $(43,44)$, especially in the liver, and normally required for special biological stealth modifications by the surface decoration of polymers such as poly(ethylene glycol) (PEG) before in vivo applications. In the present study, self-assembly of RGD4C on the nanoparticles also significantly decreased the nonspecific uptake of magnetite into the liver without additional surface modifications (Figure 4B). AAS spectroscopy also showed that nanoparticles were retained in tumor tissue for more than $48 \mathrm{~h}$ (Figure 6A), which allowed in vivo imaging tracking of the tumor. The results were consistent with those obtained from the iron-stained histological sections of cancer and normal mucosa tissues where only cancer tissues presented significant accumulation of the targeting nanoparticles. The nanoparticles went through metabolic clearance after about a week in the liver and the kidneys (Figure 6B), suggesting their safety as a targeting contrast agent with a traceable clearance mechanism.

\section{CONCLUSION}

The new concept of modular nanoparticle platform presented in this report enabled us to compile a library of targeting diagnostic and therapeutic agents (Supporting Information Figure S2). These agents could be sufficiently versatile for individual patient-based combinational assembly of the targeting moiety for a specific clinical need. They may meet the requirements of a variety of medial diagnostic and therapeutic purposes through selection of appropriate nanoparticle modules suitable for respective modalities, for example, magnetite nanoparticle for MRI in this report. This new concept may also fulfill the need of reduction in preparation time and transportation costs. It also allows prolonging of the half-life of the bionanoparticle-based agents, because the two modules can be stored separately in optimized environments before use. It is our goal to further enhance our current design so that it will make a significant contribution to advancement of translational applications using targeting nanoparticles in future medicine.

\section{ACKNOWLEDGMENT}

We thank the National Science Council of Taiwan for supporting this research with grants NSC95-95-2120-M-006013, NSC-95-2120-M-006-006, NSC-95-2314-B-006-014, and NSC94-2120-M-006-004.

Supporting Information Available: Additional information for the cytotoxicity in NIH3T3 cells and an illustration for the concept of key and key lock modular design. This material is available free of charge via the Internet at http://pubs.acs.org.

\section{LITERATURE CITED}

(1) Shapiro, E. M., Sharer, K., Skrtic, S., and Koretsky, A. P. (2006) In vivo detection of single cells by MRI. Magn. Reson. Med. $55,242-249$.

(2) Lee, J. H., and Koretsky, A. P. (2004) Manganese enhanced magnetic resonance imaging. Curr. Pharm. Biotechnol. 5, 529537.

(3) Bluemke, D. A., Sahani, D., Amendola, M., Balzer, T., Breuer, J., Brown, J. J., Casalino, D. D., Davis, P. L., Francis, I. R., Krinsky, G., Lee, F. T., Jr., Lu, D., Paulson, E. K., Schwartz, L. H., Siegelman, E. S., Small, W. C., Weber, T. M., Welber, A., and Shamsi, K. (2005) Efficacy and safety of MR imaging with liver-specific contrast agent: U.S. multicenter phase III study. Radiology 237, 89-98.

(4) Nishimura, H., Tanigawa, N., Hiramatsu, M., Tatsumi, Y., Matsuki, M., and Narabayashi, I. (2006) Preoperative esophageal cancer staging: magnetic resonance imaging of lymph node with ferumoxtran-10, an ultrasmall superparamagnetic iron oxide. J. Am. Coll. Surg. 202, 604-611.

(5) Cheng, F. Y., Su, C. H., Yang, Y. S., Yeh, C. S., Tsai, C. Y., Wu, C. L., Wu, M. T., and Shieh, D. B. (2005) Characterization of aqueous dispersions of $\mathrm{Fe}(3) \mathrm{O}(4)$ nanoparticles and their biomedical applications. Biomaterials 26, 729-38.

(6) Lee, H., Lee, E., Kim do, K., Jang, N. K., Jeong, Y. Y., and Jon, S. (2006) Antibiofouling polymer-coated superparamagnetic iron oxide nanoparticles as potential magnetic resonance contrast agents for in vivo cancer imaging. J. Am. Chem. Soc. 128, 73837389.

(7) Muller, K., Skepper, J. N., Posfai, M., Trivedi, R., Howarth, S., Corot, C., Lancelot, E., Thompson, P. W., Brown, A. P., and Gillard, J. H. (2007) Effect of ultrasmall superparamagnetic iron oxide nanoparticles (Ferumoxtran-10) on human monocytemacrophages in vitro. Biomaterials 28, 1629-1642.

(8) Lencioni, R., and Bartolozzi, C. (2004) Clinical impact of Resovist-enhanced MRI: results of an Italian multicenter trial. Eur. Radiol. 14 Suppl 1, C10.

(9) Corot, C., Robert, P., Idee, J. M., and Port, M. (2006) Recent advances in iron oxide nanocrystal technology for medical imaging. Adv. Drug Delivery Rev. 58, 1471-1504.

(10) Gohr-Rosenthal, S., Schmitt-Willich, H., Ebert, W., and Conrad, J. (1993) The demonstration of human tumors on nude mice using gadolinium-labelled monoclonal antibodies for magnetic resonance imaging. Invest. Radiol. 28, 789-795.

(11) Lee, J. H., Huh, Y. M., Jun, Y. W., Seo, J. W., Jang, J. T., Song, H. T., Kim, S., Cho, E. J., Yoon, H. G., Suh, J. S., and Cheon, J. (2007) Artificially engineered magnetic nanoparticles for ultra-sensitive molecular imaging. Nat. Med. 13, 95-99.

(12) Juang, R. S., and Wang, Y. C. (2003) Use of complexing agents for effective ion-exchange separation of $\mathrm{Co}(\mathrm{II}) / \mathrm{Ni}$ (II) from aqueous solutions. Water Res. 37, 845-852.

(13) Bhattacharyya, R., Saha, R. P., Samanta, U., and Chakrabarti, P. (2003) Geometry of interaction of the histidine ring with other planar and basic residues. J. Proteome Res. 2, 255-263.

(14) Xu, C., Xu, K., Gu, H., Zhong, X., Guo, Z., Zheng, R., Zhang, X., and Xu, B. (2004) Nitrilotriacetic acid-modified magnetic nanoparticles as a general agent to bind histidine-tagged proteins. J. Am. Chem. Soc. 126, 3392-3393.

(15) Kim, J. S., Valencia, C. A., Liu, R., and Lin, W. (2007) Highly-efficient purification of native polyhistidine-tagged proteins by multivalent NTA-modified magnetic nanoparticles. Bioconjugate Chem. 18, 333-341.

(16) Brooks, P. C., Clark, R. A., and Cheresh, D. A. (1994) Requirement of vascular integrin alpha $\mathrm{v}$ beta 3 for angiogenesis. Science 264, 569-571.

(17) Friedlander, M., Brooks, P. C., Shaffer, R. W., Kincaid, C. M., Varner, J. A., and Cheresh, D. A. (1995) Definition of two 
angiogenic pathways by distinct alpha v integrins. Science 270 , 1500-1502.

(18) Hood, J. D., and Cheresh, D. A. (2002) Role of integrins in cell invasion and migration. Nat. Rev. Cancer 2, 91-100.

(19) Jin, H., and Varner, J. (2004) Integrins: roles in cancer development and as treatment targets. Br. J. Cancer 90, 561565 .

(20) Koivunen, E., Wang, B., and Ruoslahti, E. (1995) Phage libraries displaying cyclic peptides with different ring sizes: ligand specificities of the RGD-directed integrins. Biotechnology (N. Y.) 13, 265-270.

(21) de Groot, F. M., Broxterman, H. J., Adams, H. P., van Vliet, A., Tesser, G. I., Elderkamp, Y. W., Schraa, A. J., Kok, R. J., Molema, G., Pinedo, H. M., and Scheeren, H. W. (2002) Design, synthesis, and biological evaluation of a dual tumor-specific motive containing integrin-targeted plasmin-cleavable doxorubicin prodrug. Mol. Cancer Ther. 1, 901-911.

(22) Pasqualini, R., and Ruoslahti, E. (1996) Organ targeting in vivo using phage display peptide libraries. Nature 380, 364366.

(23) Arap, W., Pasqualini, R., and Ruoslahti, E. (1998) Cancer treatment by targeted drug delivery to tumor vasculature in a mouse model. Science 279, 377-80.

(24) Hong, F. D., and Clayman, G. L. (2000) Isolation of a peptide for targeted drug delivery into human head and neck solid tumors. Cancer Res. 60, 6551-6556.

(25) Wang, F., Malac, M., and Egerton, R. F. (2006) Energy-loss nearedge fine structures of iron nanoparticles. Micron 37, 316-323.

(26) Montet, X., Montet-Abou, K., Reynolds, F., Weissleder, R., and Josephson, L. (2006) Nanoparticle imaging of integrins on tumor cells. Neoplasia 8, 214-222.

(27) de la Fuente, J. M., Berry, C. C., Riehle, M. O., and Curtis, A. S. (2006) Nanoparticle targeting at cells. Langmuir 22, 32863293.

(28) Shieh, D. B., Cheng, F. Y., Su, C. H., Yeh, C. S., Wu, M. T., Wu, Y. N., Tsai, C. Y., Wu, C. L., Chen, D. H., and Chou, C. H. (2005) Aqueous dispersions of magnetite nanoparticles with $\mathrm{NH} 3+$ surfaces for magnetic manipulations of biomolecules and MRI contrast agents. Biomaterials 26, 7183-7191.

(29) R. O.C. Patent 202070; German Patent 102004035803.

(30) Shieh, D. B., C. H. Su, C. H., Chang, F. Y., Wu, Y. N., Su, W. C., Hwu, J. R., Chen, J. H., and Yeh, C. S. (2006) Aqueous nickel-nitrilotriacetate modified $\mathrm{Fe}_{3} \mathrm{O}_{4}-\mathrm{NH}^{+3}$ nanoparticles for protein purification and cell targeting. Nanotechnology 17, 41744182.

(31) Lin, S. C., Chang, K. W., Chang, C. S., Yu, S. Y., Chao, S. Y., and Wong, Y. K. (2000) Establishment and characterization of a cell line (HCDB-1) derived from a hamster buccal pouch carcinoma induced by DMBA and Taiwanese betel quid extract. Proc. Natl. Sci. Counc., Repub. China, Part B: Basic Sci. 24, 129-135.

(32) Kim, M. S., Li, S. L., Bertolami, C. N., Cherrick, H. M., and Park, N. H. (1993) State of p53, Rb and DCC tumor suppressor genes in human oral cancer cell lines. Anticancer Res. 13, 14051413.

(33) Mosmann, T. (1983) Rapid colorimetric assay for cellular growth and survival: application to proliferation and cytotoxicity assays. J. Immunol. Methods 65, 55-63.

(34) Lin, C. L., Lee, C. F., and Chiu, W. Y. (2005) Preparation and properties of poly(acrylic acid) oligomer stabilized superparamagnetic ferrofluid. J. Colloid Interface Sci. 291, 411-420.

(35) Goede, V., Fleckenstein, G., Dietrich, M., Osmers, R. G., Kuhn, W., and Augustin, H. G. (1998) Prognostic value of angiogenesis in mammary tumors. Anticancer Res. 18, 21992202.

(36) Koh, I., Hong, R., Weissleder, R., and Josephson, L. (2008) Sensitive NMR sensors detect antibodies to influenza. Angew. Chem., Int. Ed. 47, 4119-4121.

(37) Perez, J. M., Josephson, L., O’Loughlin, T., Hogemann, D., and Weissleder, R. (2002) Magnetic relaxation switches capable of sensing molecular interactions. Nat. Biotechnol. 20, 816-820.

(38) Mulder, W. J., Koole, R., Brandwijk, R. J., Storm, G., Chin, P. T., Strijkers, G. J., de Mello Donega, C., Nicolay, K., and Griffioen, A. W. (2006) Quantum dots with a paramagnetic coating as a bimodal molecular imaging probe. Nano Lett. 6, $1-6$.

(39) Saksena, M. A., Saokar, A., and Harisinghani, M. G. (2006) Lymphotropic nanoparticle enhanced MR imaging (LNMRI) technique for lymph node imaging. Eur. J. Radiol. 58, 367-374.

(40) Thorek, D. L., Chen, A. K., Czupryna, J., and Tsourkas, A. (2006) Superparamagnetic iron oxide nanoparticle probes for molecular imaging. Ann. Biomed. Eng. 34, 23-38.

(41) Medarova, Z., Pham, W., Kim, Y., Dai, G., and Moore, A. (2006) In vivo imaging of tumor response to therapy using a dual-modality imaging strategy. Int. J. Cancer 118, 2796-2802.

(42) Sipkins, D. A., Cheresh, D. A., Kazemi, M. R., Nevin, L. M., Bednarski, M. D., and Li, K. C. (1998) Detection of tumor angiogenesis in vivo by alphaVbeta3-targeted magnetic resonance imaging. Nat. Med. 4, 623-626.

(43) Kreuter, J. (1994) Drug targeting with nanoparticles. Eur. J. Drug Metab. Pharmacokinet. 19, 253-256.

(44) Araujo, L., Lobenberg, R., and Kreuter, J. (1999) Influence of the surfactant concentration on the body distribution of nanoparticles. J. Drug Targeting 6, 373-385.

BC800092W 